\title{
Natural Leishmania (Viannia) infections of phlebotomines (Diptera: Psychodidae) indicate classical and alternative transmission cycles of American cutaneous leishmaniasis in the Guiana Shield, Brazil
}

\author{
Adelson Alcimar Almeida de Souza ${ }^{1, \dagger}$, Iorlando da Rocha Barata ${ }^{1}$, Maria das Graças Soares Silva ${ }^{1, \dagger}$, \\ José Aprígio Nunes Lima ${ }^{1}$, Yara Lúcia Lins Jennings ${ }^{1}$, Edna Aoba Yassui Ishikawa ${ }^{2}$, Ghislaine Prévot ${ }^{3}$, \\ Marine Ginouves $^{3}$, Fernando Tobias Silveira ${ }^{1,2}$, Jeffrey Shaw ${ }^{4}$, and Thiago Vasconcelos dos Santos, ${ }^{1, *}$ \\ 1 Seção de Parasitologia, Instituto Evandro Chagas (Secretaria de Vigilância em Saúde, Ministério da Saúde), Ananindeua, \\ zip code 67.030-000 Pará State, Brazil \\ 2 Núcleo de Medicina Tropical, Universidade Federal do Pará, Belém, zip code 66055-240 Pará State, Brazil \\ 3 Département de Médecine, Ecosystèmes Amazoniens et Pathologie Tropicale, EA 3593, Labex CEBA, Université de Guyane, \\ zip code 97300 Cayenne, French Guiana \\ 4 Instituto de Ciências Biomédicas, Universidade de São Paulo, zip code 05508-000 São Paulo, Brazil
}

Received 15 March 2017, Accepted 17 April 2017, Published online 15 May 2017

\begin{abstract}
From 1996 to 1999 multi-trapping methods (Center of Diseases Control, CDC) light traps, light-baited Shannon traps, and aspiration on tree bases) were used to study the phlebotomine fauna of the "Serra do Navio" region of the Brazilian State of Amapá, which is part of the Guiana Shield. Fifty-three species were identified among 8,685 captured individuals. The following species, associated with the transmission of American cutaneous leishmaniasis in Amazonian Brazil, were captured: Nyssomyia umbratilis (3,388), Psychodopygus squamiventris maripaensis (995), Ny. anduzei (550), Trichophoromyia ubiquitalis (400), Ny. whitmani (291), Ps. paraensis (116), and Bichromomyia flaviscutellata (50). Flagellate infections were detected in 45 flies. Of the 19 parasites isolated in vitro, 15 were Leishmania (Viannia) guyanensis (13 in Ny. umbratilis, 1 in Ny. whitmani, 1 in Ny. anduzei) and three were L. (V.) naiffi (2 in Ps. s. maripaensis, 1 in Ny. anduzei). The results indicate the participation of three phlebotomine species in the transmission of $L$. (V.) guyanensis and two species in that of $L$. (V.) naiffi, and show that the same phlebotomine species is involved in the transmission of different Leishmania (Viannia) species in the Guianan/ Amazon region. A review of the literature together with the results of the present study, and other published and unpublished results, indicate that eight phlebotomine species potentially participate in the transmission of Leishmania (Viannia) naiffi in Amazonia.
\end{abstract}

Key words: Phlebotomine, Natural infection, Leishmania, Guiana Shield.

Résumé - L'infection naturelle de phlébotomes (Diptera, Psychodidae) par Leishmania (Viannia) révèle l'existence de cycles classique et alternatif de transmission de la leishmaniose cutanée sur le plateau des Guyanes au Brésil. De 1996 à 1999 plusieurs méthodes de piégeage (pièges lumineux CDC, pièges Shannon et aspirations à la base des arbres) ont été utilisées afin d'étudier les populations de phlébotomes de la région "Serra do Navio" dans l'état brésilien de l'Amapà, qui fait partie du plateau des Guyanes. Cinquante-trois espèces ont été identifiées parmi les 8,685 individus capturés. Plusieurs espèces associées à la transmission de la leishmaniose cutanée américaine en Amazonie brésilienne ont été capturées : Nyssomyia umbratilis $(3,388)$, Psychodopygus squamiventris maripaensis (995), Ny. anduzei (550), Trichophoromyia ubiquitalis (400), Ny. whitmani (291), Ps. paraensis (116) et Bichromomyia flaviscutellata (50). L'infection par des flagellés a été détectée chez quarantecinq individus. Parmi les 19 isolés in vitro, 15 étaient Leishmania (Viannia) guyanensis (13 chez Ny. umbratilis, 1 chez $N y$. whitmani, 1 chez $N y$. anduzei) et trois étaient L. (V.) naiffi (2 chez Ps. s. maripaensis, $1 \mathrm{chez} N y$. anduzei). Ces résultats indiquent l'implication de trois espèces de phlébotomes dans la transmission de $L$. $(V$.) guyanensis et de deux espèces dans la transmission de L. (V.) naiffi et montrent que la même espèce de

\footnotetext{
In memoriam.

*Corresponding author: thiagovasconcelos@iec.pa.gov.br
}

This is an Open Access article distributed under the terms of the Creative Commons Attribution License (http://creativecommons.org/licenses/by/4.0), which permits unrestricted use, distribution, and reproduction in any medium, provided the original work is properly cited. 
phlébotome est impliquée dans la transmission de plusieurs espèces de Leishmania (Viannia) dans la région guyanoamazonienne. Une revue de la littérature associée aux résultats de la présente étude et à des résultats publiés et non publiés montre que 8 espèces de phlébotomes participent potentiellement à la transmission de Leishmania (Viannia) naiffi en Amazonie.

\section{Introduction}

The Guiana Shield is a geological formation with various ecological areas within the Amazon biome of Venezuela (Delta Amacuro, Bolívar, and Amazonas States), Brazil (Northern Amapá, Pará, Roraima, and Amazonas States), Guyana, Suriname, and the Overseas Department of French Guiana. Its environmental conditions sustain some specific ecological niches and it is one of the regions with the highest biodiversity in the world [49]. Such characteristics favor an array of vectorreservoir relationships and consequently a mosaic of leishmanian ecosystems [55].

American cutaneous leishmaniasis (ACL) is endemic in the region and so far, five dermotropic coexisting Leishmania species have been found there: Leishmania (Viannia) guyanensis Floch 1954, L. (V.) braziliensis Vianna 1911, L. (Leishmania) amazonensis Lainson and Shaw 1972, L. (V.) lainsoni Silveira et al. 1987, and L. (V.) naiffi Lainson and Shaw 1989 [55]. L. (V.) guyanensis is the most frequent, accounting for over $80 \%$ of ACL cases. However, in French Guiana, for example, recently [43] other species have been found associated with an emerging ACL pattern $[L$. (V.) lainsoni - 1.4\%, L. (L.) amazonensis $-2.6 \%$, L. (V.) braziliensis $-8.8 \%$ ]. These findings are of concern as they indicate ecological changes that favor the transmission of other parasites associated with debilitating forms of the disease, such as diffuse and mucocutaneous leishmaniasis.

Despite the high incidence of ACL in Amapá State (AP) [64], there is a paucity of ecological studies on its vectors and reservoirs. The state is bordered by northern Pará State to the west and French Guiana to the northwest, where the ecology of the disease has been studied more extensively $[16,33,39,43,54,55]$. There are only a few studies on the phlebotomines associated with ACL transmission in AP $[5,15,17,18,46,58]$. The aim of the present survey of the Serra do Navio phlebotomine population is in part to fill this gap by assessing putative transmission cycles in this Brazilian region of the Guiana Shield.

\section{Materials and methods}

\section{Study area}

Serra do Navio $\left(00^{\circ} 53^{\prime} \quad 45^{\prime \prime} \quad \mathrm{N} ; \quad 52^{\circ} 00^{\prime} 07^{\prime \prime} \mathrm{W}\right.$, $148 \mathrm{~m}$ a.s.l) is one of the 16 municipalities that constitute AP (Northern Brazil). It is in the central area of AP and is $146 \mathrm{~km}$ from the state capital, Macapá. Its area is approximately $7,757 \mathrm{~km}^{2}$ and it has an estimated population of 4,761 [26] (Fig. 1). The climate is similar to those of the other
Amazonian ecoregions of the Guiana Shield, as follows: a short rainy season from mid-November to late January; a short dry season between early February and mid-March; a long rainy season from late March to late July; and a long dry season from late July to mid-November.

Historically, this location is an area of mineral exploitation. In the 1950s the "Sociedade Brasileira de Indústria e Comércio de Minérios de Ferro e Manganês" (ICOMI), in association with Bethlehem Steel, began the manganese mining operation that came to a premature end in 1997. A mining complex was built together with a modern residential township. A health department was set up to look after the health of the mine workers. It was exceptionally efficient and well organized and its team of doctors dealt easily with most of the normal health problems. However, the greatest immediate risks to this isolated population were endemic diseases such as malaria and ACL. The careful use of chloroquinized salt successfully protected them from malaria but no similar measures were or are available against ACL. Today, Serra do Navio is a municipality of intense ACL transmission. During a 2002 epidemiological study, the ACL coefficient of infection was 1,476/100,000 inhabitants [8]. Capture sites were located in three areas of primary forest that were less than $10 \mathrm{~km}$ from urban areas. These undisturbed environments were considered to be ecologically similar and were therefore treated as a single site. These areas were predominantly covered by submontane (lowland), dense forest.

\section{Field and laboratory procedures on phlebotomines}

Captures were performed during five 12-night expeditions in 1996 (May and September), 1997 (July and November), and 1999 (October). Traps were installed as follows along transects in forested areas from the edge inwards: eight "Center of Diseases Control" (CDC) light traps set each night at $1.5 \mathrm{~m}$ above ground level (6) and at $20 \mathrm{~m}$ in the canopy (2), from 06:00 pm to 06:00 am; light-bait Shannon traps, between 06:00 pm and 08:00 pm; and captures on tree bases with a battery-operated aspirator from 07:00 am to 09:00 am. The number of capture hours was calculated by multiplying the number of traps set by the number of hours of exposure. After screening, all phlebotomine females were dissected under sterile conditions as described by Ryan et al. [56]. Males were stored in $70 \%$ alcohol. If there was any difficulty in identifying a dissected female, it was mounted in Berlese fluid (GBI Laboratories). Species were identified using Young and Duncan's guide [74] and the nomenclature adopted is in accordance with the taxonomic criteria proposed by Galati [21]. Two letter genus abbreviations are those suggested by Marcondes [42]. 


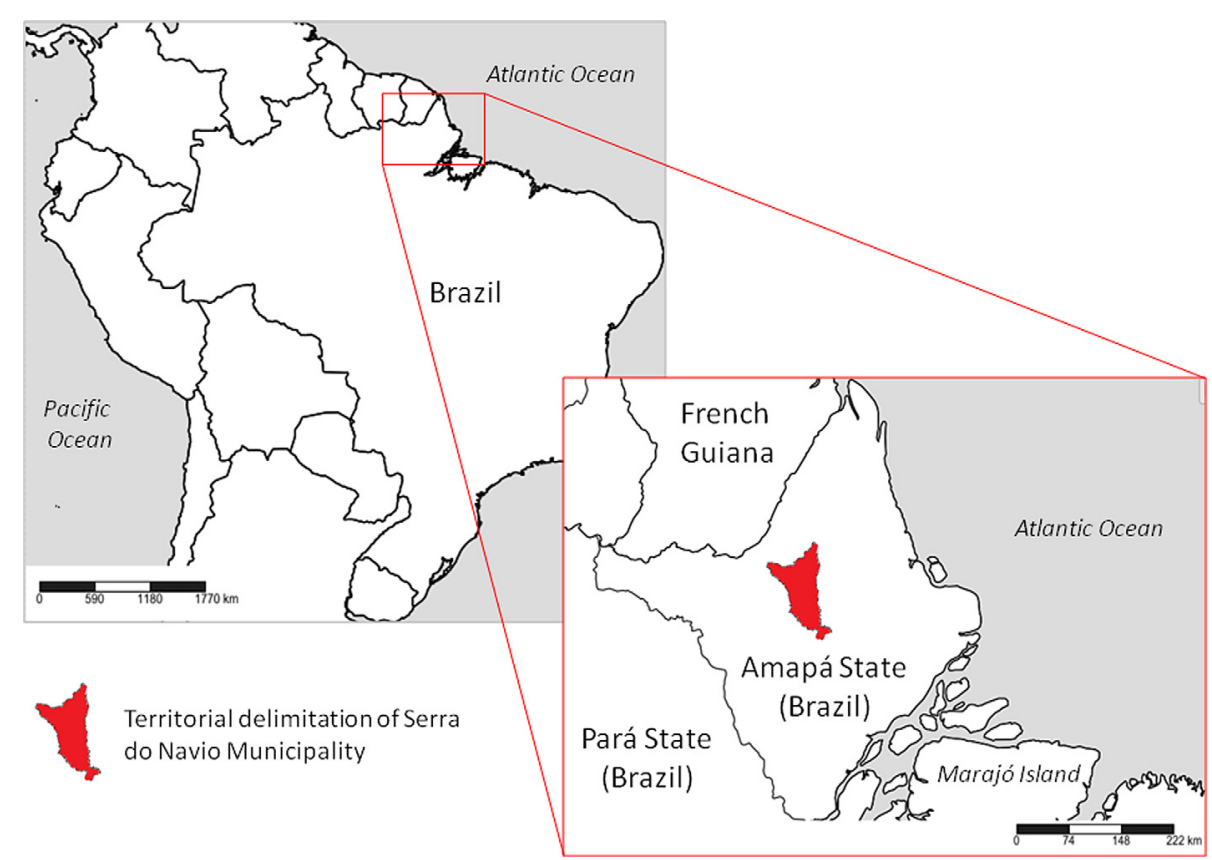

Figure 1. Study area, placed in a Guianan/Amazon forested environment of Serra do Navio municipality, Amapá State, Brazil.

Species composition in the four different trapping samples was analyzed using the Shannon-Wiener diversity index $\left(H^{\prime}\right)$ and dominance $(D)$, with the aid of the statistical software Past version 2.12 [25].

\section{Characterization of flagellate strains}

The dissected female digestive tracts were examined microscopically for flagellates. Infections were classified according to their distribution in the intestine and semi-quantified using the parasitosis scale adopted by Freitas et al. [17]. After this, the intestine was homogenized and inoculated into two culture tubes containing Difco $\mathrm{B}^{45}$ [72]. Isolates were initially characterized by the use of a panel of 23 monoclonal antibodies by a fluorescein-labeled avidin indirect immunofluorescence method (IIF-McAb reaction), as described by Shaw et al. [59]. Phenotypic characterization was undertaken by isoenzyme electrophoresis for ${ }_{6} \mathrm{PGDH}$ (E.C 1.1.1. 44), PGM (E.C 5.4.2.2), and MPI (E.C 5.3.1.8) as described by Miles et al. [45], and/or by polymerase chain reaction-restriction fragment length polymorphism analysis (PCR-RFLP) of a $615 \mathrm{bp}$ amplified region of the RNA polymerase II gene digested with endonucleases TpsRI and HgaI, as per Simon et al. [63].

$\mathrm{McAb}$, isoenzymatic, and PCR-RFLP profiles of the isolates were compared with those of the five World Health Organization (WHO) reference strains known to occur in the Guiana Shield, L. (L.) amazonensis (IFLA/BR/1967/PH8), L. (V.) braziliensis (MHOM/BR/1975/M2903), L. (V.) guyanensis (MHOM/BR/1975/M4147), L. (V.) naiffi (MDAS/BR/1979/ M5533), and L. (V.) lainsoni (MHOM/BR/1981/M6426), as well as with the other WHO reference strains of ecologically closely related species: L. (V.) shawi shawi (MCEB/BR/1984/ M8408) and L. (V.) lindenbergi (MHOM/BR/1998/15732).

\section{Results}

The composition of the phlebotomine fauna is summarized in Table 1. A total of 8,685 phlebotomines belonging to 55 taxa were captured by the four trapping methods; of these, 53 were identified to species or subspecies level. Females $(6,212)$ predominated over males $(2,473)$. The species were distributed among 15 genera: Psathyromyia (Pa., 10 spp.), Psychodopygus (Ps., 8 spp), Evandromyia (Ev., 7 spp.), Nyssomyia (Ny., 6 spp.), Micropygomyia (Mi., 3 spp.), Brumptomyia (Br., 3 spp), Lutzomyia (Lu., 3 spp), Pintomyia (Pi., 3 spp.), Sciopemyia (Sc., 2 spp), Trichophoromyia (Th., 2 spp), Trichopygomyia (Ty., 1 sp.), Viannamyia (Vi., 2 spp), Bichromomyia (Bi., 1 spp), Migonemyia (Mg., 1 sp.), and Pressatia (Pr., 1 sp). CDC ground captures provided the highest diversity $(H=2.627)$, followed by Shannon traps $(2.126)$, aspiration on tree bases (1.795), and CDC canopy (1.671).

Ny. umbratilis (3,388), Ps. s. maripaensis (995), Ny. anduzei (550), Th. ubiquitalis (400), Ny. whitmani (291), and Ps. paraensis (116) were among the ten most frequent species. The dominance $(D=0.402)$ was due to high numbers of Ny. umbratilis in canopy CDCs.

The average of phlebotomine putative vector species captured per hour can be found in Table 2. Considering all capture methods, captures of $N y$. umbratilis (0.64) were the greatest, followed by Ps. squamiventris maripaensis (0.19). However, when each trap was compared individually, Shannon captures were higher for Ps. s. maripaensis (11.5), Ny umbratilis (5.33), and Ny. anduzei (3.48). 
Table 1. Species composition, diversity, and infection rate of the Phlebotomine fauna in the Serra do Navio, Amapá State, Brazil, from 1996 to 1999 .

\begin{tabular}{|c|c|c|c|c|c|c|c|c|c|c|c|c|}
\hline \multirow[t]{2}{*}{$S$} & \multirow[t]{3}{*}{ Phlebotomine species } & \multicolumn{8}{|c|}{ Capture method } & \multirow[t]{3}{*}{ Total } & \multirow[t]{3}{*}{$\%$} & \multirow[t]{3}{*}{ SIR } \\
\hline & & \multicolumn{2}{|c|}{ CDC ground } & \multicolumn{2}{|c|}{ CDC canopy } & \multicolumn{2}{|c|}{ Shannon } & \multicolumn{2}{|c|}{ Tree bases } & & & \\
\hline & & 우운 & $\hat{0} \hat{0}$ & oqo & $\hat{0} \hat{0}$ & 우 & $\hat{\sigma o x}$ & oq & $\hat{0} \hat{0}$ & & & \\
\hline 1 & Ny. umbratilis (33) & $524(10)$ & 123 & $1,634(12)$ & 731 & $130(3)$ & 190 & $16(8)$ & 40 & 3,388 & 38.43 & 1.43 \\
\hline 2 & Ps. squamiventris maripaensis (2) & 156 & 12 & $134(1)$ & 1 & $627(1)$ & 63 & 1 & 1 & 995 & 11.45 & 0.21 \\
\hline 3 & Ev. infraspinosa & 580 & 36 & 1 & 1 & 5 & 3 & & & 626 & 7.2 & - \\
\hline 4 & Ny. pajoti (2) & $61(2)$ & 16 & 230 & 46 & 101 & 161 & 1 & 4 & 620 & 7.13 & 0.5 \\
\hline 5 & Ny. anduzei (2) & $39(1)$ & 40 & $189(1)$ & 73 & 26 & 183 & & & 550 & 6.33 & 0.78 \\
\hline 6 & Th. ubiquitalis & 183 & 138 & 8 & 4 & 31 & 36 & & & 400 & 4.6 & - \\
\hline 7 & Ny. whitmani (3) & $42(1)$ & 13 & 168 & 12 & 13 & 2 & $4(2)$ & 37 & 291 & 3.35 & 1.32 \\
\hline 8 & Ty. trichopyga & 56 & 95 & 24 & 16 & 7 & 5 & & & 203 & 2.33 & - \\
\hline 9 & Ps. hirsutus & 32 & 26 & 48 & & 40 & 12 & & & 158 & 1.93 & - \\
\hline 10 & Vi. tuberculata & 44 & & 94 & & 2 & & 1 & & 141 & 1.62 & - \\
\hline 11 & Ps. paraensis & 24 & 2 & 39 & 2 & 41 & 8 & & & 116 & 1.33 & - \\
\hline 12 & Ev. bacula & 15 & & 56 & 2 & 17 & 24 & & & 114 & 1.31 & - \\
\hline 13 & Vi. furcata & 47 & & 46 & 1 & 10 & 2 & & & 106 & 1.22 & - \\
\hline 14 & Lu. gomezi (1) & 38 & 2 & 11 & 2 & $18(1)$ & 1 & 4 & 27 & 103 & 1.18 & 1.4 \\
\hline 15 & Ps. davisi & 23 & 8 & 38 & 5 & 13 & 8 & & & 95 & 1.09 & - \\
\hline 16 & Pa. aragaoi & 47 & 20 & 19 & 3 & & 2 & & & 91 & 1.04 & - \\
\hline 17 & Th. brachipyga & 27 & 34 & 3 & 1 & 5 & 2 & & & 72 & 0.82 & - \\
\hline 18 & Ps. amazonensis & 16 & 3 & 24 & 4 & 24 & & & & 71 & 0.81 & - \\
\hline 19 & Pa. scaffi & & 4 & & & & & 8 & 57 & 69 & 0.79 & - \\
\hline 20 & Ps. geniculatus & 19 & 2 & 14 & & 14 & 3 & & & 52 & 0.59 & - \\
\hline 21 & Bi. flaviscutellata & 18 & 12 & 7 & 1 & 10 & 2 & & & 50 & 0.57 & - \\
\hline- & Brumptomyia spp. & 17 & & 29 & & & & & & 46 & 0.52 & - \\
\hline 22 & Pa. barretoi barretoi & 1 & 24 & & 10 & & 1 & & & 36 & 0.41 & - \\
\hline 23 & Ps. claustrei & 6 & 4 & 6 & & 15 & & & & 31 & 0.35 & - \\
\hline 24 & Pa. dendrophyla & 14 & 1 & 13 & & 1 & 1 & & 1 & 31 & 0.35 & - \\
\hline 25 & Ev. monstruosa & 13 & 1 & 1 & & 12 & & & & 27 & 0.31 & - \\
\hline 26 & Ev. evandroi & 15 & & 2 & & 2 & & & & 19 & 0.21 & - \\
\hline 27 & Mg. migonei (1) & $2(1)$ & & 8 & 7 & & 2 & & & 19 & 0.21 & 10 \\
\hline 28 & Pi. damascenoi & 8 & & 2 & & 6 & & & 2 & 18 & 0.20 & - \\
\hline 29 & Pa. runoides & 9 & 2 & 1 & 1 & 1 & & & & 14 & 0.16 & - \\
\hline 30 & Pa. bigeniculata & 4 & & 1 & 1 & & & 2 & 6 & 14 & 0.16 & - \\
\hline 31 & Mi. rorotaensis & 4 & 1 & & & 1 & & 5 & 3 & 14 & 0.16 & - \\
\hline 32 & Mi. micropyga & 9 & & 1 & & 1 & & & & 11 & 0.12 & - \\
\hline 33 & Sc. sordellii (1) & 5 & 1 & 1 & & $2(1)$ & 1 & & & 10 & 0.11 & 12.5 \\
\hline 34 & Ev. sericea & 5 & 4 & & 1 & & & & & 10 & 0.11 & - \\
\hline 35 & Pa. dreisbachi & & & 1 & 8 & & & & & 9 & 0.10 & - \\
\hline 36 & Pr. trispinosa & 1 & 6 & 1 & & & & & & 8 & 0.09 & - \\
\hline 37 & Lu. carvalhoi & 4 & & 2 & & 1 & & & & 7 & 0.08 & - \\
\hline 38 & Lu. spatotrichia & 1 & & 3 & 1 & & 1 & & & 6 & 0.06 & - \\
\hline 39 & Ps. carrerai & 2 & 2 & 1 & & 1 & & & & 6 & 0.06 & - \\
\hline 40 & Ny. antunesi & 2 & 1 & & & & & & 2 & 5 & 0.05 & - \\
\hline 41 & Ev. inpai & 1 & 3 & & & & & & & 4 & 0.04 & - \\
\hline 42 & Pa. lutziana & 2 & & 1 & 1 & & & & & 4 & 0.04 & - \\
\hline 43 & Pa. inflata & 1 & 2 & 1 & & & & & & 4 & 0.04 & - \\
\hline 44 & Sc. fluviatilis & 2 & & & & 2 & & & & 4 & 0.04 & - \\
\hline 45 & Br. travassosi & & 2 & & 1 & & & & & 3 & 0.03 & - \\
\hline 46 & Pi. serrana & & & 2 & & 1 & & & & 3 & 0.03 & - \\
\hline 47 & Ny. richardwardi & 1 & & 1 & & & & & & 2 & 0.02 & - \\
\hline 48 & Pa. abonnenci & & 1 & & 1 & & & & & 2 & 0.02 & - \\
\hline 49 & Mi. pilosa & 2 & & & & & & & & 2 & 0.02 & - \\
\hline 50 & Br. beaupertuyi & & 2 & & & & & & & 2 & 0.02 & - \\
\hline 51 & Ev. brachyphalla & 1 & & & & & & & & 1 & 0.01 & - \\
\hline 52 & Pi. pacae & & & & 1 & & & & & 1 & 0.01 & - \\
\hline 53 & Br. pintoi & & 1 & & & & & & & 1 & 0.01 & - \\
\hline & Total & 2,123 & 644 & 2,865 & 938 & 1,180 & 713 & 42 & 180 & 8,685 & & \\
\hline
\end{tabular}


Table 1. (continued)

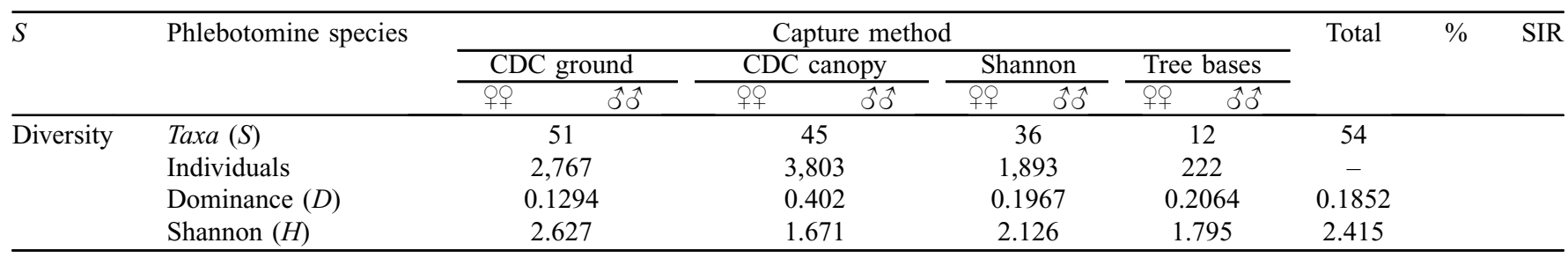

(): Number of individuals found with natural infection by flagellates; 우: females; $\widehat{\jmath} \widehat{\jmath}:$ males; bold, species associated with ACL agents occurring in the Guiana Shield on the basis of current literature [6, 16, 53, 55, 65]; SIR: Species Infection Rate.

Table 2. Average of phlebotomine putative vector species captured per hour in the Serra do Navio, Amapá State, Brazil, from 1996 to 1999.

\begin{tabular}{|c|c|c|c|c|c|}
\hline \multirow[t]{2}{*}{ Phlebotomine putative vector species } & \multicolumn{4}{|c|}{ Capture method* } & \multirow[t]{2}{*}{ Total** } \\
\hline & CDC ground & CDC canopy & Shannon & $\overline{\text { Tree bases }}$ & \\
\hline Ny. umbratilis & 0.17 & 1.64 & 5.33 & 0.93 & 0.64 \\
\hline Ps. squamiventris maripaensis & 0.04 & 0.09 & 11.5 & 0.03 & 0.19 \\
\hline Ny. anduzei & 0.02 & 0.18 & 3.48 & - & 0.10 \\
\hline Th. ubiquitalis & 0.08 & 0.008 & 1.11 & - & 0.07 \\
\hline Ny. whitmani & 0.01 & 0.12 & 0.25 & 0.68 & 0.05 \\
\hline Ps. paraensis & 0.007 & 0.02 & 0.81 & - & 0.02 \\
\hline Bi. flaviscutellata & 0.008 & 0.005 & 0.2 & - & 0.009 \\
\hline
\end{tabular}

* Based on 3,600 h CDC ground, 1,440 h CDC canopy, $60 \mathrm{~h}$ Shannon, and $60 \mathrm{~h}$ of aspiration on tree bases;

** Based on $5,160 \mathrm{~h}$ of total trapping.

There was no evidence of blood in the intestines of the 45 infected females and the parasitosis ranged from 21-40 (+++) to 41 or above $(++++)$ flagellates per field (40× objective). From their morphology, we were unable to confirm that any of these trypanosomatids were Leishmania.

Flagellates were found in $0.72 \%$ of the females $(45 / 6,212)$ : 33/2,304 Ny. umbratilis (12-CDC canopy, 10-CDC ground, 8-Tree bases, 3-Shannon; species infection rate: 1.43); 2/918 Ps. s. maripaensis (1-CDC canopy, 1-Shannon; species infection rate: $0.21 \%$ ); $3 / 227 \mathrm{Ny}$. whitmani (2-Tree bases, 1 -CDC ground; species infection rate: $1.32 \%) ; 2 / 254 N y$. anduzei (1-CDC ground, 1-CDC canopy; species infection rate: $0.78 \%) ; 2 / 393$ Ny. pajoti (CDC ground; species infection rate: $0.5 \%$ ); $1 / 10$ $\mathrm{Mg}$. migonei (CDC ground; species infection rate: 10\%); 1/71 Lu. gomezi (Shannon; species infection rate: 1.4\%); and 1/8 Sc. sordellii (Shannon; species infection rate: 12.5\%).

Nineteen flagellate strains were successfully isolated. Fifteen were identified as $L$. (V.) guyanensis from $N y$. umbratilis (13), Ny. whitmani (1), and Ny. anduzei (1), and three as L. (V.) naiff from Ps. s. maripaensis (2) and Ny. anduzei (1) (Table 3). Both Leishmania species had the same McAb profiles as the WHO reference strains MHOM/BR/1975/M4147 and MDAS/BR/1979/M5533. The Mg. migonei isolate (IMIG/BR/1997/M16230) did not react with any of the McAbs. The identifications of the $N y$. anduzei (IAND/BR/ 1997/M16408) isolate as L. (V.) naiffi and the Ny. whitmani (IWHI/BR/1997/M16399) isolate as L. (V.) guyanensis were confirmed by ${ }_{6} \mathrm{PGDH} / \mathrm{PGM} / \mathrm{MPI}$ isoenzyme electrophoresis (Fig. 2) and PCR-RFLP analysis (Fig. 3). Table 4 gives a list of $L$. (V.) naiffi phlebotomine infections prepared from the results of this study and other published records.

\section{Discussion}

Amapá State is one of Brazil's most environmentally preserved regions and the present survey of its phlebotomine fauna amplifies the findings of previous researchers $[1,5,15$, 17, 18, 19, 20, 46, 48, 57, 74]. Five species [Ev. bacula (Martins, Falcão \& Silva, 1965), Pa. runoides (Farchild \& Hertig, 1953), Ps. carrerai (Barretto, 1946), Br. beaupertuyi (Ortiz, 1954) (first record for Brazil), and $B r$ pintoi (Costa Lima, 1932)] were recorded for the first time in this state by this study. Thus, Aguiar and Medeiros' [1] checklist, which records 55 species for AP, needs updating.

The first records for phlebotomines in the Serra do Navio were produced in the 1960s from collections by JE Silva (unpublished). Young and Duncan [74] and Ward and Fraiha [73] referred to collections made by D. Young in the 1970 s, but there are no checklists for this municipality. The specimens collected by JE Silva are deposited in René Rachou's phlebotomine collection (FIOCRUZ, Belo Horizonte, Minas Gerais, Brazil) and some of them have been used for the description of Micropygomyia pusilla (Dias, Martins Falcão \& Silva, 1986) [11]. This species, however, was not found in the present survey.

The highest richness of species was observed for Psathyromyia and Psychodopygus, among the 15 genera captured in 
Table 3. Naturally infected phlebotomine species and their respective results for Leishmania spp. isolation/characterization in the Serra do Navio, Amapá State, Brazil, from 1996 to 1999.

\begin{tabular}{|c|c|c|c|c|c|c|}
\hline $\mathrm{N}$ & IEC code & Phlebotomine species & $\begin{array}{c}\text { Collection data } \\
\text { (trapping/site) }\end{array}$ & Result* & MCAb reaction-profile & WHO Code \\
\hline 1 & M 15928 & Ny. umbratilis & Shannon & Negative/contaminated & - & - \\
\hline 2 & M 15929 & Sc. sordellii & Shannon & Negative/contaminated & - & - \\
\hline 3 & M 15930 & Lu. gomezi & Shannon & Negative/contaminated & - & - \\
\hline 4 & M 15931 & Ny. umbratilis & CDC canopy & L. (V.) guyanensis & L1; B2; B12V; B19 & IUMB/BR/1996/M15931 \\
\hline 5 & M 15932 & Ny. yuilli pajoti & CDC ground & Negative/contaminated & - & - \\
\hline 6 & M 15933 & Ny. umbratilis & CDC ground & Negative/contaminated & - & - \\
\hline 7 & M 15934 & Ny. umbratilis & CDC ground & Negative/contaminated & - & - \\
\hline 9 & M 15935 & Ny. umbratilis & CDC ground & Negative/contaminated & - & - \\
\hline 9 & M 15936 & Ny. yuilli pajoti & CDC ground & Negative/contaminated & - & - \\
\hline 10 & M 16230 & Mg. migonei & $\mathrm{CDC}$ ground & ? & No reaction & IMIG/BR/1997/M16230 \\
\hline 11 & M 16231 & Ny. umbratilis & CDC ground & Negative/contaminated & - & - \\
\hline 12 & M16232 & Ny. umbratilis & Shannon & Negative/contaminated & - & - \\
\hline 13 & M 16233 & Ny. umbratilis & CDC canopy & Negative/contaminated & - & - \\
\hline 14 & M 16234 & Ny. umbratilis & Shannon & Negative/contaminated & - & - \\
\hline 15 & M 16235 & $\begin{array}{l}\text { Ps. squamiventris } \\
\text { maripaensis }\end{array}$ & CDC canopy & L. (V.) naiffi & L1; B12; N2; N3 & ISQU/BR/1997/M16235 \\
\hline 16 & M 16390 & Ny. umbratilis & CDC canopy & L. (V.) guyanensis & L1; B2; B12V; B19 & IUMB/BR/1997/M16390 \\
\hline 17 & M 16391 & Ny. umbratilis & CDC canopy & L. (V). guyanensis & L1; B2; B12V; B19 & IUMB/BR/1997/M16391 \\
\hline 18 & M 16392 & Ny. umbratilis & CDC canopy & Negative/contaminated & - & - \\
\hline 19 & M 16393 & Ny. umbratilis & CDC canopy & Negative/contaminated & - & - \\
\hline 20 & M 16394 & Ny. umbratilis & CDC ground & Negative/contaminated & - & - \\
\hline 21 & M 16395 & Ny. umbratilis & CDC ground & Negative/contaminated & - & - \\
\hline 22 & M 16396 & Ny. umbratilis & CDC canopy & Negative/contaminated & - & - \\
\hline 23 & M 16397 & Ny. umbratilis & CDC canopy & Negative/contaminated & - & - \\
\hline 24 & M 16398 & Ny. umbratilis & CDC ground & L. (V.) guyanensis & L1; B2; B12V; B19 & IUMB/BR/1997/M16391 \\
\hline 25 & M 16399 & Ny. whitmani & CDC ground & L. (V.) guyanensis & L1; B2; B12V; B19 & IWHI/BR/1997/M16399 \\
\hline 26 & M 16400 & Ny. umbratilis & $\mathrm{CDC}$ ground & L. (V.) guyanensis & $\mathrm{L} 1 ; \mathrm{B} 2 ; \mathrm{B} 12 \mathrm{~V} ; \mathrm{B} 19$ & IUMB/BR/1997/M16400 \\
\hline 27 & M 16402 & Ny. umbratilis & CDC canopy & L. (V.) guyanensis & L1; B2; B12V; B19 & IUMB/BR/1997/M16401 \\
\hline 28 & M 16403 & $N y$. anduzei & CDC ground & L. (V.) guyanensis & L1; B2; B12V; B19 & IAND/BR/1997/M16403 \\
\hline 29 & M 16404 & Ny. umbratilis & CDC ground & Negative/contaminated & - & - \\
\hline 30 & M 16405 & Ny. umbratilis & CDC ground & L. (V.) guyanensis & L1; B2; B12V; B19 & IUMB/BR/1997/M16405 \\
\hline 31 & M 16406 & Ny. umbratilis & CDC canopy & Negative/contaminated & - & - \\
\hline 32 & M 16407 & Ps. s. maripaensis & Shannon & L. (V.) naiffi & L1; B12; N2; N3 & ISQU/BR/1997/M16407 \\
\hline 33 & M 16408 & Ny. anduzei & CDC canopy & L. (V.) naiffi & $\mathrm{L} 1 ; \mathrm{B} 12 ; \mathrm{N} 2 ; \mathrm{N} 3$ & IAND/BR/1997/M16408 \\
\hline 34 & M 16409 & Ny. umbratilis & CDC canopy & L. (V.) guyanensis & $\mathrm{L} 1 ; \mathrm{B} 2 ; \mathrm{B} 12 \mathrm{~V} ; \mathrm{B} 19$ & IUMB/BR/1997M16409 \\
\hline 35 & M 16410 & Ny. umbratilis & CDC canopy & L. (V.) guyanensis & $\mathrm{L} 1 ; \mathrm{B} 2 ; \mathrm{B} 12 \mathrm{~V} ; \mathrm{B} 19$ & IUMB/BR/1997/M16410 \\
\hline 36 & M 17944 & Ny. whitmani & Tree bases & Negative/contaminated & - & - \\
\hline 37 & M 17945 & Ny. whitmani & Tree bases & Negative/contaminated & - & - \\
\hline 38 & M 17946 & Ny. umbratilis & Tree bases & L. $(V$.$) guyanensis$ & L1; B2; B12V; B19 & IUMB/BR/1999/M17946 \\
\hline 39 & M 17947 & Ny. umbratilis & Tree bases & L. (V.) guyanensis & $\mathrm{L} 1 ; \mathrm{B} 2 ; \mathrm{B} 12 \mathrm{~V} ; \mathrm{B} 19$ & IUMB/BR/1999/M17947 \\
\hline 40 & M 17948 & Ny. umbratilis & Tree bases & Negative/contaminated & - & - \\
\hline 41 & M 17949 & Ny. umbratilis & Tree bases & Negative/contaminated & - & - \\
\hline 42 & M 17950 & Ny. umbratilis & Tree bases & Negative/contaminated & - & - \\
\hline 43 & M 17951 & Ny. umbratilis & Tree bases & Negative/contaminated & - & - \\
\hline 44 & M 17952 & Ny. umbratilis & Tree bases & L. (V.) guyanensis & L1; B2; B12V; B19 & IUMB/BR/1999/M17952 \\
\hline 45 & M 17953 & Ny. umbratilis & Tree bases & L. (V.) guyanensis & $\mathrm{L} 1 ; \mathrm{B} 2 ; \mathrm{B} 12 \mathrm{~V} ; \mathrm{B} 19$ & IUMB/BR/1999/M17953 \\
\hline
\end{tabular}

* Based on McAb, isoenzyme, and PCR-RFLP profiles.

Serra do Navio. The former also included four species from the Shannoni series Fairchild, 1955, whose taxonomic status has recently been revised [57]. Voucher specimens originally identified as Pa. shannoni (Dyar, 1929) (MGS Silva det.) were re-examined and after further consultation (AJ Andrade, personal communication), it was concluded that they in fact represent the resurrected Pa. bigeniculata (Floch \& Abonnenc, 1941).
The role of different phlebotomine species in ACL epidemiology in the Guiana Shield contrasts with that of the Amazonian lowlands. In the latter region, Psychodopygus species appear to be the dominant vectors, whereas in the Guiana Shield, it is the Nyssomyia species that dominate.

As might be expected, the principal vector of $L$. (V.) guyanensis, Ny. umbratilis, stands out in the list of vectors, in accordance with several other studies in highly endemic 

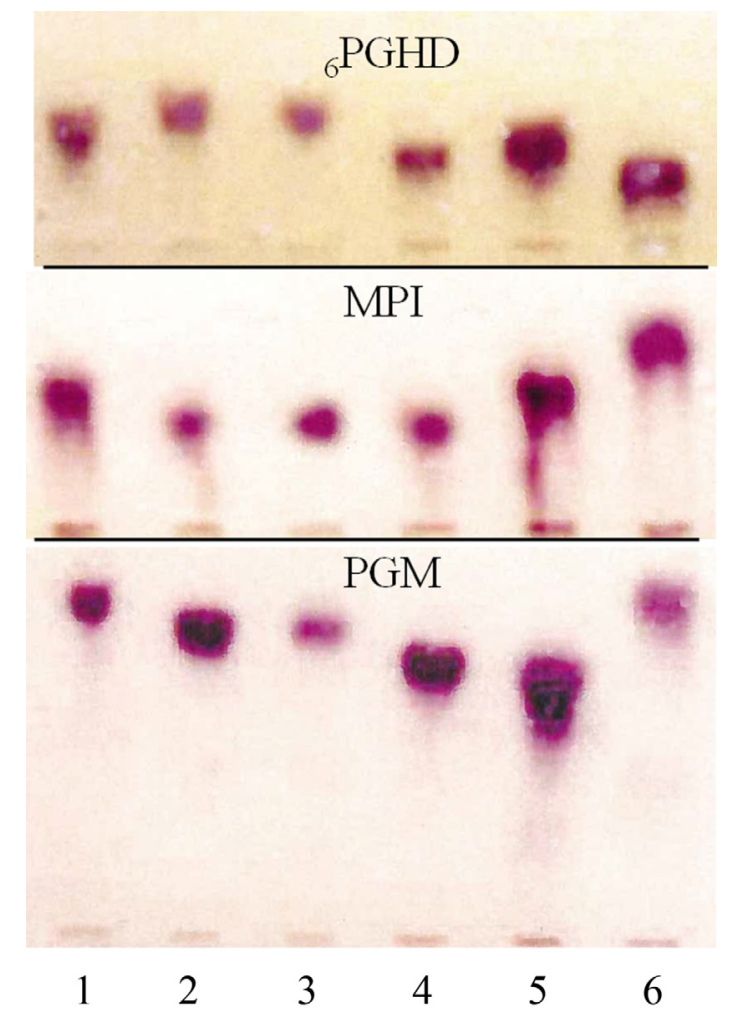

Figure 2. Isoenzyme electrophoresis of 6PGDH, MPI, and PGM enzymatic systems for the isolate from Nyssomya whitmani in the "Serra do Navio", Amapá State, Brazil, compared with the WHO reference strains of Brazilian Amazon Leishmania species. Reading from left to right: (1) L. (V.) braziliensis (MHOM/BR/1975/M2903); (2) IWHI/BR/1997/M16399; (3) L. (V.) guyanensis (MHOM/BR/ 1975/M4147); (4) L. (V.) s. shawi (MCEB/BR/1984/M8408); (5) L. (V.) naiffi (MDAS/BR/1979/M5533); (6) L. (V.) lainsoni (MHOM/BR/1981/M6426).

ACL regions [33, 50, 51]. A part of the life cycle of Ny. umbratilis is arboreal, and this is highlighted by its dominant presence in our canopy traps. In an area affected by a hydroelectric dam project on the Jari River (AP), no differences were observed between ground level and canopy catches for this species. This could be because most arboreal animals, which are the principal blood source for this species, were removed during environmental management operations related to the destruction of the forest [18]. Unfortunately, present captures are logistically biased which often weakens conclusions on seasonality. However, we found that $N y$. umbratilis, including infected individuals, was only taken from tree trunks at ground level during the dry season. Our data on the treedwelling behavior of $\mathrm{Ny}$ umbratilis are compatible with those on the well-studied populations of the Northern Amazon $[39,54,73]$. The morphologically closely related species found in smaller numbers, $N y$. anduzei, behaves similarly and it has been suggested that it is a secondary $L$. ( V.) guyanensis vector in ACL foci where Ny. umbratilis is present [53].

Ps. s. maripaensis has been associated with $L$. (V.) naiffi in northern Brazil [47] and French Guiana [16], and has been suggested as a possible vector of $L$. (V.) braziliensis and $L$. (V.) naiffi in Suriname [30]. Its high numbers in our Shannon captures

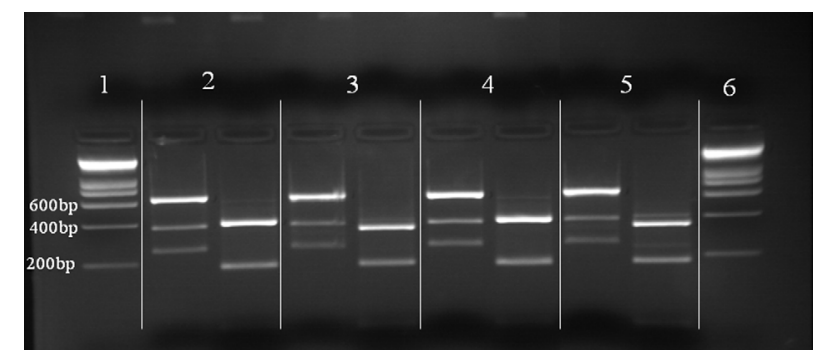

Figure 3. PCR-RFLP analysis of Leishmania isolates from Nyssomyia whitmani and Nyssomyia anduzei in the "Serra do Navio", Amapá State, Brazil, compared with the closely related WHO reference strains of Brazilian Amazon Leishmania species, $L$. (V.) guyanensis and $L$. (V.) naiffi. Reading from left to right: (1) Molecular weight marker Smart Ladder ${ }^{\circledR}$; (2) L. (V.) guyanensis (MHOM/BR/1975/M4147); (3) L. (V.) naiffi (MDAS/BR/1979/ M5533); (4) IWHI/BR/1997/M16399; (5) IAND/BR/1997/ M16408; (6) Molecular weight marker Smart Ladder ${ }^{\circledR}$.

suggest its anthropophilic behavior and preference for populations living at ground level. Catchers in the Shannon traps constantly found this species trying to bite them despite the use of protective measures. Two infections in Ps. s. maripaensis (Shannon and CDC canopy) were characterized as L. (V.) naiffi. Human infections with this parasite are unknown in AP, but these findings are proof that its enzootic is present in the Serra do Navio forest. Records also link its known distribution to this Leishmania species in the Brazilian states of Amazonas [23, 47], Acre [61], Rondônia [2, 22], Pará [35] and the belt that includes AP, French Guiana [55], and Suriname [69]. Interestingly, single records for $L$. $(V$.$) naiffi have also been reported$ in Ecuador [29], Peru, Martinique (inconclusive?) [52], and Panama [3].

Leishmania DNA has been found in some Trichophoromyia species and their possible importance in ACL epidemiology has been discussed [30, 44, 67]. Th. ubiquitalis is the proven vector of $L$. (V.) lainsoni $[53,62]$ and its potential importance in ACL epidemiology in AP is supported by the fact that $L$. (V.) lainsoni has been diagnosed in patients from this state (FT Silveira, personal observations).

In Pará State, $N y$. whitmani is associated with transmission of L. (V.) shawi shawi [32] and latterly Lu. gomezi has been indicated as a putative vector of this same parasite [65]. However, Ny. whitmani has also been associated with the L. (V.) guyanensis enzootic in the Monte Dourado region of the Guiana Shield [33]. In the north-eastern and Atlantic forest region of Brazil, $N y$. whitmani is an important vector of $L$. (V.) braziliensis $[4,6,70]$. In these environments, $N y$. whitmani occurs predominantly in peri-domestic situations. Its sylvatic occurrence in the present study is in accordance with early studies [35, 60], and may represent a typical Amazonian population also present in French Guiana [41] and Suriname [30]. One of the three infections found in Ny. whitmani was characterized as L. (V.) guyanensis. Lainson et al. [33] found five infections of $L$. (V) guyanensis in Ny. whitmani from the Monte Dourado in northern Pará State. These and our results reignite the intriguing hypothesis of Lainson et al. [33] who suggested that $N y$. whitmani may play a vector role together with 
Table 4. Present and literature-based Leishmania (Viannia) naiffi detection in phlebotomine species.

\begin{tabular}{llll}
\hline \multicolumn{1}{c}{ Phlebotomine species } & \multicolumn{1}{c}{ Location } & L. (V.) naiffi typing & Reference \\
\hline Ps. ayrozai (3) & BR 319, Km 866 (RO), BR & MLEE & Arias et al. (1985) [2] \\
Ps. paraensis (4) & BR 319, Km 866 (RO), BR & MLEE & Arias et al. (1985) [2] \\
Ps. squamiventris s.l. (1) & Balbina (AM), BR & MLEE & Grimaldi et al. (1991) [23] \\
Ps. squamiventris s.l. (1) & Cachoeira Porteira (PA), BR & MLEE & Grimaldi et al. (1991) [23] \\
Ps. paraensis (1) & Benevides (PA) & MLEE & Silveira et al. (1991) [62] \\
Ps. ayrozai & Benevides (PA) & MLEE & Silveira et al. (1991) [62] \\
Ps. davisi & Cacaulândia (RO), BR & McAb & Gil et al. (2003) [22] \\
Ps. hirsutus & Cacaulândia (RO), BR & McAb & Gil et al. (2003) [22] \\
Ps. s. maripaensis (1) & Sinnamary, FG & RNA poly II gene sequencing & Fouque et al. (2007) [16] \\
Lu. tortura (1) & Arajuno, EC & Cyt b gene sequencing & Kato et al. (2008) [29] \\
Ps. davisi (2) & Belterra (PA), BR & McAb/MLEE & Souza et al. (2016) [65] \\
Ps. hirsutus (1) & Belterra (PA), BR & McAb/MLEE & Souza et al. (2016) [65] \\
Ps. wellcomei/complexus (1) & Belterra (PA), BR & McAb/RNA poly II gene sequencing & Unpublished \\
Ny. anduzei (1) & Serra do Navio (AP), BR & McAb/RNA poly II gene PCR-RFLP & Present study \\
Ps. s. maripaensis (2) & Serra do Navio (AP), BR & McAb/RNA poly II gene PCR-RFLP & Present study \\
\hline
\end{tabular}

Notes. All Leishmania (Viannia) naiff detections were based on microscopic analysis of dissected flies and further in vitro (direct culture) and/or in vivo (inoculation in hamster prior culture) parasite isolation. (): number of infected specimens, when available; McAb: Monoclonal antibodies; MLEE: Multilocus enzyme electrophoresis; poly II: polymerase II; (AM): Amazonas State; (AP): Amapá State; (PA): Pará State; (RO): Rondônia State; BR; Brazil; EC: Ecuador; FG: French Guiana; SU: Suriname.

Ny. umbratilis in the transmission of $L$. (V.) guyanensis. Moreover, in AP, a single infection from $N y$. umbratilis captured near Porto Grande was also compatible with $L$. (V.) guyanensis by morphology and behavior in hamsters [17]. Rangel and Lainson [53] suggested that flagellates found by Lainson et al. [33] in Ny. whitmani could have been L. (V.) shawi. Our characterizations by three different methods (IIF-McAb, isoenzyme electrophoresis, and PCR-RFLP) of the isolates from the three available $N y$. whitmani collected in 1981, that Rangel and Lainson [53] referred to, were all confirmed to be $L$. (V.) guyanensis. From this, we conclude that it is very unlikely that L. (V.) shawi occurs in the Guiana Shield, as indicated in [55] and that Ny. whitmani in fact contributes to L. (V.) guyanensis transmission.

There is strong evidence that $N y$. whitmani sensu lato is genetically complex [27], with regional differences in the behavior of distinct geographical populations [7]. Its status as a species complex is presently being discussed and it is quite possible that the Guiana Shield population represents a distinct genetic group. Recent results demonstrating the lower Amazon's "leishmanian bridging zone", where L. (V.) shawi shawi and L. (V.) guyanensis coexist, as well as a $L$. (V.) guyanensis/L. (V.) shawi shawi hybrids [28], support the idea of a genetically different $N y$. whitmani population in the Guiana Shield.

Natural infections of Ps. paraensis found in other regions of the Amazon support its role as a potential vector of $L$. (V.) naiff $[2,34]$. However, the absence of such infections in the 104 Ps. paraensis in the present work does not negate the presence of $L$. (V.) naiffi in Serra do Navio.

The finding of $L$. ( V.) guyanensis in a specimen of Bi. flaviscutellata from French Guiana [16] raises speculations of potential changes in transmission in the Guiana Shield. The main reason for this is that the classical vectors are arboreal and Bi. flaviscutellata is a ground-loving species. One hypothesis is that there are L. (V.) guyanensis infections in both arboreal and terrestrial mammals. L. (L.) amazonensis has been found in this phlebotomine as well as in small mammals and humans in the Guiana Shield [9, 55, 68]. Absence of infections in this species in the present study could be misleading and explained by the fact that only 35 females were dissected. The small numbers in catches are perhaps related to this fly being less attracted to light traps [37]. However, in other situations, CDC sets installed at ground level have collected significant numbers of Bi. flaviscutellata $[14,20]$.

The present rate of $1.43 \%$ of Leishmania-like infections in Ny. umbratilis, with 13 infections proven to be $L$. (V.) guyanensis, is in accordance with other surveys conducted in French Guiana with 1.3\% [40] and Amazons State with $1.04 \%$ [51], but higher frequencies were reported in the former territory $(15 \%)$ [39], as well as in a nearby area on the outskirts of Porto Grande (26\%) [17]. These facts do not merely consolidate the role of this species as the main ACL vector in AP, but make us aware of a factual risk of Serra do Navio being a hotspot for ACL transmission. Reported ACL cases have been identified early as being caused by this parasite in the region [23]. In addition, two strains isolated from ACL patients (MHOM/BR/1996/M15781; MHOM/BR/1996/ M15937), likely infected in Serra do Navio, with diagnosis performed by our team at the time of field expeditions, were typed by the IIF-McAb technique as $L$. (V.) guyanensis and are identical to our $N y$. umbratilis isolates (unpublished observations). The feasible classical mechanism of diurnal infection documented involves females resting on tree bases, and when humans come close to these ecotopes, they may disturb the insects that start aggressive biting behaviors [50].

Single L. (V.) guyanensis infection in Ny. anduzei is consistent with its apparently secondary participation in the transmission cycle of Guianan ACL. However, the first finding of this fly harboring $L$. (V.) naiff raises the interesting hypothesis of an increasing demand for candidates for transmitting 
this parasite. Another species, Ps. hirsutus (Mangabeira, 1942), has also recently been included in the large list of "microscopically based" suspected vectors of $L$. (V.) naiffi [65], which is already composed of the other psychodopygians Ps. paraensis, Ps. ayrozai (Barretto \& Coutinho, 1940), and Ps. squamiventris s.l., Ps. davisi (Root, 1934), and even the lutzomyian member, Lu. tortura Young \& Rogers, 1984 [2, 22, 23, 29, 36, 62] (Table 4). "Molecular-based" vector speculations were not included in the former list due to their questionable ability to determine true infection, as recently argued by Brazil et al. [6]. The lack of Leishmania typing methods in AP means that our conclusions are biased toward the hypothesis that $L$. (V.) guyanensis is the principal etiological agent of ACL. However, it is reasonable to assume that ACL cases due to $L$. (V.) naiffi are underreported in AP as it is normally self-healing and there is no routine identification of ACL parasites. Different ecological situations may affect the incidence of this form of ACL, and in Amazonas State, two of eight $L$. (V.) naiffi cases did not respond to initial treatment [12].

Two individuals of $N y$. pajoti from CDC ground were found infected with Leishmania-like flagellates, which were not successfully cultured. This species harbors an unidentified Leishmania species [10, 31, 74]. Its arboreal behavior coincides with those of $N y$. umbratilis, $N y$. anduzei, and $N y$. whitmani, all of which have been shown to be infected with $L$. (V.) guyanensis. This leads us to speculate that the two unknown flagellates in Ny. pajoti were also L. (V.) guyanensis. These four fly species were all captured in ground level CDCs, increasing their potential role as vectors to humans during the night.

Despite medical evidence highlighting $M g$. migonei as a vector of $L$. (V.) braziliensis in north-eastern and south-eastern Brazil [53], there are no signs of its implication in the context of leishmaniasis in the Amazon region. The isolate from this species was compatible with an unknown trypanosomatid which should be better characterized in the future. Moreover, another similar infection in $\mathrm{Mg}$. migonei was recently found during an entomological study in Oiapoque, far north of AP, and although parasite isolation failed, DNA was obtained from the slide used for dissection. In both situations, the PCR-RFLP technique was negative, confirming that these parasites are distinct from Leishmania (TV Santos, M Ginouves, G Prévot, personal observation).

Failure of flagellate isolation occurred with Sc. sordellii and Lu. gomezi. Regarding Sc. sordellii, this is not of concern for the ecology of ACL because infection of this species is historically recognized as being caused by other non-Leishmania trypanosomatids [56], and even further PCR-based findings of Leishmania DNA within this fly [24, 38] did not suggest a determinant role in the transmission of leishmaniasis. In the case of $L u$. gomezi, however, its epidemiological relevance as a vector of $L$. $(V$.$) panamensis outside the Brazilian Amazon$ $[13,66,71]$ and PCR-based suspicion of it carrying L. (V.) naiffi in Panama [3] raise the hypothesis that it may be competent in harboring Leishmania species from the Guiana Shield. This speculation is supported by its early infection by unidentified flagellate in French Guiana [9], as well as by our findings of a single specimen that proved to be infected with L. (V.) shawi shawi in the lower Amazon region [65].
Trapping methods favor different species, resulting in a bias that portrays the enzootic and/or the zoonotic cycle. In the present study, CDC light trap catches were the highest, but they were set for a greater number of hours. When the captures were corrected for the number per/hour (Table 2), the numbers of Ny. umbratilis, PS. s. maripaensis, and Ny. anduzei captured in the Shannon trap exceeded those of the CDCs. Even though we were unable to identify all the flagellates found in these three species, we consider that our present and past results add weight to their importance as ACL vectors.

The present results provide an update on the phlebotomine fauna inventory of AP and indicate putative ACL vectors for the region. L. (V.) guyanensis infections in $N y$. umbratilis and $N y$. anduzei confirmed them, respectively, as primary and secondary vectors. Our analysis of passed infections of Ny. whitmani suggests that this species may also participate in the transmission scenario. On the other hand, the circulation of L. (V.) naiffi in Ps. s. maripaensis, which is highly anthropophilic, raises the possibility of the occurrence of underreported ACL cases related to this parasite. The finding of $L$. (V.) naiffi in $N y$. anduzei adds yet another vector to the long list (Table 4) of suspected vectors of this parasite. The absence of infections in Bi. flaviscutellata and Th. ubiquitalis does not exclude their possible involvement in ACL transmission in AP. Both are well-known vectors in a nearby region, being associated, respectively, with $L$. (L.) amazonensis and $L$. (V.) lainsoni.

Clinical data suggest that the highest risk of infection in AP is from the L. (V.) guyanensis enzootic via a mosaic of vectors, and from the $L$. (V.) lainsoni enzootics. However, the presence of species considered as putative or proven vectors indicates that there is also a risk of infection from the $L$. $(V$.) braziliensis, L. (V.) naiffi, and $L$. (L.) amazonensis enzootic cycles, and that more than one vector may be involved in each cycle. It remains to be seen whether the unidentified infections represent infections of known Leishmania species in other phlebotomines or infections of new parasite species.

\section{Conflict of interest}

The authors declare that they have no conflict of interest.

Acknowledgements. The authors gratefully acknowledge José Itamar de Almeida, Raimundo Nonato Barbosa Pires, Antônio Francisco Pires Martins, and João Batista Palheta da Luz (IEC/ SVS/MS, Pará, Brazil) for their technical assistance and Fernando Guimarães, José Luiz Ortiz Virgolino, and José Augusto Araújo (ICOMI/IRDA, AP, Brazil) for the logistical support provided in field work. The authors also appreciate the collaboration of Andrey José de Andrade (UFPR, Paraná, Brazil) for his advice with the Psathyromyia determination. Financial support was provided by the Instituto Evandro Chagas/SVS/MS, ICOMI/IRDA, EPaT/ Université de Guyane, and CNR leishmaniose.

\section{References}

1. Aguiar GM, Medeiros WM. 2003. Distribuição regional e hábitats das espécies de flebotomíneos do Brasil, in Flebotomíneos do Brasil, Rangel EF, Lainson R, Organizators. Fiocruz, Rio de Janeiro. p. 207-255. 
2. Arias JR, Miles MA, Naiff RD, Póvoa MM, de Freitas RA, Biancardi CB, Castellón EG. 1985. Flagellate infections of Brazilian sand flies (Diptera: Psychodidae): isolation in vitro and biochemical identification of Endotrypanum and Leishmania. American Journal of Tropical Medicine and Hygiene, 34, 1098-1110.

3. Azpurua J, de la Cruz D, Valderama A, Windsor D. 2010. Lutzomyia sand fly diversity and rates of infection by Wolbachia and an exotic Leishmania species on Barro Colorado Island, Panama. PlosOne, 4, e627.

4. Brandão-Filho SP, Brito ME, Carvalho FG, Ishikawa EA, Cupolillo E, Floeter-Winter L, Shaw JJ. 2003. Wild and synanthropic hosts of Leishmania (Viannia) braziliensis in the endemic cutaneous leishmaniasis locality of Amaraji, Pernambuco State, Brazil. Transactions of the Royal Society of Tropical Medicine and Hygiene, 97, 291-296.

5. Brazil RP, Andrade Filho JD, Falcão AL. 2000. Notes on Phlebotomine sandflies (Diptera; Psychodidae) from Amapá state, Brazil. Journal of the American Mosquito Control Association, 16, 40-41.

6. Brazil RP, Rodrigues AAF, Andrade Filho JD. 2015. Sand fly vectors of Leishmania in the Americas - A mini review. Entomology, Ornithology and Herpetology, 4, 144.

7. Campbell-Lendrum DH, Brandão-Filho SP, Pinto MC, Vexenat AJ, Ready PD, Davies CR. 2000. The domesticity of Lutzomyia whitmani populations: field experiments indicate behavioural differences. Bulletin of Entomological Research, 90, 41-48.

8. Chaves RCG. 2003. Avaliação epidemiológica da leishmaniose tegumentar Americana no estado do Amapá em 2002. Revista da Sociedade Brasileira de Medicina Tropical, 36(suppl. 2), 25-26.

9. Dedet JP, Pajot FX, Desjeux P, Goyot P, Chippaux JP, Geoffroy B. 1985. Natural hosts of Leishmania mexicana amazonensis Lainson and Shaw, 1972 (Kinetoplastida: Trypanosomatidae) in French Guiana. Transactions of the Royal Society of Tropical Medicine and Hygiene, 79, 302-305.

10. Dedet JP. 1990. Cutaneous leishmaniasis in French Guiana: a review. American Journal of Tropical Medicine and Hygiene, 43, 25-28.

11. Dias ES, Martins AV, Falcão AL, Silva JE. 1986. Descrição de uma nova espécie do subgênero Helcocyrtomyia, Lutzomyia pusilla sp. n. (Diptera: Psychodidae: Phlebotominae). Memórias do Instituto Oswaldo Cruz, 81, 395-399.

12. Fagundes-Silva GA, Romero GAS, Cupolillo E, Yamashita EPG, Gomes-Silva A, Guerra JAO, Da-Cruz AM. 2015. Leishmania (Viannia) naiffi: rare enough to be neglected? Memórias do Instituto Oswaldo Cruz, 110, 797-800.

13. Feliciangeli MD, Rabinovich J. 1998. Abundance of Lutzomyia ovallesi but not Lu. gomezi (Diptera: Psychodidae) correlated with cutaneous leishmaniasis incidence in north-central Venezuela. Medical and Veterinary Entomology, 12, 121-131.

14. Ferreira JVS, Santos TV, Gorayeb IS. 2014. Phlebotomine sand flies (Diptera: Psychodidae) in forest fragments of Belém metropolitan area, Pará State, Brazil, with considerations on vectors of American cutaneous leishmaniasis agents. Revista Pan-Amazônica de Saude, 5, 29-35.

15. Forattini OP. 1959. Sobre os flebótomos do território do Amapá, Brasil. Separata dos arquivos da Faculdade de Higiene e Saúde Pública da Universidade de São Paulo, 3, $158-164$.

16. Fouque F, Gaborit P, Issaly J, Carinci R, Gantier J-C, Ravel C, Dedet J-P. 2007. Phlebotomine sand flies (Diptera:
Psychodidae) associated with changing patterns in the transmission of the human cutaneous leishmaniasis in French Guiana. Memórias do Instituto Oswaldo Cruz, 102(1), 35-40.

17. Freitas RA, Naiff RD, Barret TV. 2002. Species diversity and flagellate infections in the sand fly fauna near Porto Grande, State of Amapá, Brazil (Diptera: Psychodidae. Kinetoplastida: Trypanosomatidae). Memórias do Instituto Oswaldo Cruz, 9, 53-59.

18. Furtado NVR, Galardo AKR, Galardo CD, Firmino VC, dos Santos TV. 2016. Phlebotomines (Diptera: Psychodidae) in a hydroelectric system affected area from Northern Amazonian Brazil: Further insights into the effects of environmental changes on vector ecology. Journal of Tropical Medicine, 2016, 9819723.

19. Galardo AKR, Galardo CD, Santana AA, Mendes JCC, Souza FRA, Duarte JP, Saraiva JF, Pinna LCL, Carvalho RW, Correa APSA, Lima ACSF. 2013. Primeira ocorrência de Lutzomyia (Lutzomyia) longipalpis Lutz \& Neiva, 1912 (Diptera: Psychodidae: Phlebotominae) no Estado do Amapá, Brasil. Biota Amazonia, 3, 179-183.

20. Galardo AKR, Galardo CD, Silveira GA, Ribeiro KAN, Hijjar AV, Oliveira AL, Santos TV. 2015. Phlebotominae sand flies (Diptera: Psychodidae): potential vectors of American cutaneous leishmaniasis agents in the area associated with the Santo Antônio hydroelectric system in Western Amazonian Brazil. Revista da Sociedade Brasileira de Medicina Tropical, 48, 265-271.

21. Galati EAB. 2003. Morfologia e Taxonomia: Morfologia, terminologia de adultos e identificação táxons da América, in Flebotomíneos do Brasil, Rangel EF, Lainson R, Organizators. Fiocruz, Rio de Janeiro. p. 23-206.

22. Gil LH, Basano AS, Souza AA, Silva MG, Barata I, Ishikawa EA, Camargo LM, Shaw JJ. 2003. Recent observations on the sand fly (Diptera: Psychodidae) fauna of the state of Rondônia, western Amazonia, Brazil: the importance of Psychodopygus davisi as a vector of zoonotic cutaneous leishmaniasis. Memórias do Instituto Oswaldo Cruz, 98, 751-755.

23. Grimaldi G Jr, Momen H, Naiff RD, McMahon-Pratt D, Barrett TV. 1991. Characterization and classification of leishmanial parasites from humans, wild mammals, and sand flies in the Amazon region of Brazil. American Journal of Tropical Medicine and Hygiene, 44, 645-661.

24. Guimarães VCFV, Costa PC, Silva FJ, Melo FL, Dantas-Torres F, Rodrigues EHG, Brandão Filho SP. 2014. Molecular detection of Leishmania in phlebotomine sand flies in a cutaneous and visceral leishmaniasis endemic area in northeastern Brazil. Revista do Instituto de Medicina Tropical de São Paulo, 56, 357-360.

25. Hammer Ø, Harper DAT, Ryan PD. 2001. PAST: Paleontological Statistics Software Package for Education and Data Analysis. Paleontologia Electronica, 4, 1-9.

26. IBGE (Instituto Brasileiro de Geografia e Estatística. 2013. Coordenação de População e Indicadores Sociais (1st July 2013). "Estimates of resident population in the Brazilian municipalities dated July 1, 2013". Consulted in 9th September 2013. Available from http://www.ibge.gov.br

27. Ishikawa EA, Ready PD, de Souza AA, Day JC, Rangel EF, Davies CR, Shaw JJ. 1999. A mitochondrial DNA phylogeny indicates close relationships between populations of Lutzomyia whitmani (Diptera: Psychodidae, Phlebotominae) from the rainforest regions of Amazonia and northeast Brazil. Memórias do Instituto Oswaldo Cruz, 94, 339-345. 
28. Jennings YL, de Souza AAA, Ishikawa EA, Shaw J, Lainson R, Silveira FT. 2014. Phenotypic characterization of Leishmania spp. causing cutaneous leishmaniasis in the lower Amazon region, western Pará state, Brazil, reveals a putative hybrid parasite, Leishmania (Viannia) guyanensis $\times$ Leismania (Viannia) shawi shawi. Parasite, 21, 39.

29. Kato H, Gomez EA, Yamamoto Y, Calvopiña M, Guevara AG, Marco JD, Barroso PA, Iwata I, Hashiguchi Y. 2008. Natural infection of Lutzomyia tortura with Leishmania (Viannia) naiffi in an Amazonian area of Ecuador. American Journal of Tropical Medicine and Hygiene, 79, 438-440.

30. Kent A, Santos TV, Gandadin A, Samjhawan A, Mans DRA, Schallig HDFH. 2013. Studies on the sand fly fauna (Diptera: Psychodidae) in high-transmission areas of cutaneous leishmaniasis in the Republic of Suriname. Parasites \& Vectors, 6, 318.

31. Killick-Kendrick R. 1990. Phlebotomine vectors of the leishmaniasis: a review. Medical and Veterinary Entomology, 4, 1-24.

32. Lainson R, Braga RR, Souza AA, Povoa MM, Ishihawa EAY, Silveira FT. 1989. Leishmania (Viannia) shawi sp. n., a parasite of monkeys, sloths and procyonids in Amazonian Brazil. Annales de Parasitologie Humaine et Comparée, 64, 200-207.

33. Lainson R, Shaw JJ, Ready PD, Miles MA, Póvoa M. 1981. Leishmaniasis in Brazil: XVI. Isolation and identification of Leishmania species from sand flies, wild mammals and man in north Pará state, with particular reference to L. braziliensis guyanensis causative agent of "pian-bois". Transactions of the Royal Society of Tropical Medicine and Hygiene, 75, 530-536.

34. Lainson R, Shaw JJ, Silveira FT, Braga RR, Ishikawa EAY. 1990. Cutaneous leishmaniasis of man due to Leishmania (Viannia) naiffi. Annales de Parasitologie Humaine et Comparée, 65, 282-284.

35. Lainson R, Shaw JJ, Ward RD, Ready PD, Naiff RD. 1979. Leishmaniasis in Brazil: XIII. Isolation of Leishmania from armadillos (Dasypus novemcinctus) and observation on the epidemiology of cutaneous leishmaniasis in north Pará state. Transactions of the Royal Society of Tropical Medicine and Hygiene, 73, 239-242.

36. Lainson R, Shaw JJ. 1989. Leishmania (Viannia) naiffi sp. n., a parasite of the armadillo, Dasypus novemcinctus in Amazonian Brazil. Annales de Parasitologie Humaine et Comparée, 64, 3-9.

37. Lainson R, Shaw JJ. 1968. Leishmaniasis in Brazil I. Observations on enzootic rodent leishmaniasis - Incrimination of Lutzomyia flaviscutellata (Mangabeira) as the vector in the lower Amazonian basin. Transactions of the Royal Society of Tropical Medicine and Hygiene, 62, 385-395.

38. Lana RS, Michalsky EM, Fortes-Dias CR, França-Silva JC, Lara-Silva FO, Lima ACVMR, Avelar DM, Martins JCD, Dias ES. 2015. Phlebotomine sand fly fauna and Leishmania infection in the vicinity of the Serra do Cipó National Park, a natural Brazilian heritage site. BioMed Research International, 2015, 385493.

39. Le Pont F, Pajot FX. 1980. La leishmaniose en Guyane Française. I. Étude de l'écologie et du taux d'infection naturelle d'un vecteur Lutzomyia (Nyssomyia) umbratilis Ward et Fraiha, 1977 en saison sèche. Considerations epidémiologiques. Cahiers ORSTOM Série Entomologie Médicale et Parasitologie, 18, 359-383.

40. Le Pont F, Pajot FX, Reguer R. 1980. Preliminary observations on the silvatic cycle of leishmaniasis in French Guiana. Transactions of the Royal Society of Tropical Medicine and Hygiene, 74, 133.
41. Léger N, Abonnenc E, Pajot FX, Kramer R, Claustre J. 1977. Liste commentée des phlébotomes de la Guyane Française. Cahiers ORSTOM Série Entomologie Médicale et Parasitologie, 15, 217-232.

42. Marcondes CB. 2007. A proposal of generic and subgeneric abbreviations for Phlebotomine Sandflies (Diptera: Psychodidae: Phlebotominae) of the World. Entomological News, 118, 351-356.

43. Martin-Blondel G, Iriart X, El Baidouri F, Simon S, Mills D, Demar M, Pistone T, Le Taillandier T, Malvy D, Gangneux J-P, Couppie P, Munckhof W, Marchou B, Ravel C, Berry A. 2015. Outbreak of Leishmania braziliensis Cutaneous Leishmaniasis, Saül, French Guiana. Emerging Infectious Diseases, 21, 893-894.

44. Martinez E, Le Ponte F, Mollinedo S, Cupollilo EA. 2001. First case of cutaneous leishmaniasis due to Leishmania (Viannia) lainsoni in Bolivia. Transactions of the Royal Society of Tropical Medicine and Hygiene, 95, 375-377.

45. Miles MA, Póvoa MM, Souza AA, Lainson R, Shaw JJ. 1980. Some methods for the enzymic characterization of LatinAmerican Leishmania with particular reference to Leishmania mexicana amazonensis and subspecies of Leishmania hertigi. Transactions of the Royal Society of Tropical Medicine and Hygiene, 74, 243-252.

46. Moreno ES, Freire MP, Nascimento LOC, Zanini V, Zanini V, Alves VR, Shimabukuro PHF. 2013. Sand flies (Diptera, Psychodidae, Phlebotominae) collected in the Waiãpi indigenous reserve, Eastern Amazon, Brazil. Abstract Book ISOPS VIII - International Symposium on Phlebotomine Sandflies, Puerto Iguazú, Argentina, ID20-P.

47. Naiff RD, Freitas RA, Naiff MF, Arias JR, Barret TV, Momen H, Grimaldi JuniorG. 1991. Epidemiological and nosological aspects of Leishmania naiffi Lainson \& Shaw, 1989. Memórias do Instituto Oswaldo Cruz, 86, 317-321.

48. Oliveira AG, Andrade Filho JD, Falcão AL. 2001. A new sand fly, Lutzomyia campograndensis sp. n. (Diptera: Psychodidae: Phlebotominae) from the State of Mato Grosso do Sul, Brazil. Memórias do Instituto Oswaldo Cruz, 96, 325-329.

49. Olson DM, Dinerstein E, Wikramanayake ED, Burgess ND, Powell GVN, Underwood EC, d'Amico JA, Itoua I, Strand HE, Morrison JC, Loucks CJ, Allnutt TF, Ricketts TH, Kura Y, Lamoreux JF, Wettengel WW, Hedao P, Kassem KR. 2001. Terrestrial ecoregions of the world: a new map of life on earth. Bioscience, 51, 933-938.

50. Pajot FX, Le Pont F, Gentile B, Besnard R. 1982. Epidemiology of leishmaniasis in French Guiana. Transactions of the Royal Society of Tropical Medicine and Hygiene, 76, 112-113.

51. Pinheiro FG, Luz SLB, Franco AMR. 2008. Infecção natural por tripanosomatídeos (Kinetoplastida: Trypanosomatidae) em Lutzomyia umbratilis (Diptera: Psychodidae) em áreas de leishmaniose tegumentar americana no Amazonas, Brasil. Acta Amazonica, 38, 165-172.

52. Pratlong F, Deniau M, Darie H, Eichenlaub S, Proll S, Garrabe E, le Guyadec T, Dedet JP. 2002. Human cutaneous leishmaniasis caused by Leishmania naiffi is wide-spread in South America. Annals of Tropical Medicine and Parasitology, 96, 781-785.

53. Rangel EF, Lainson R. 2009. Proven and putative vectors of American cutaneous leishmaniasis in Brazil: aspects of their biology and vectorial competence. Memórias do Instituto Oswaldo Cruz, 104, 937-995. 
54. Ready PD, Lainson R, Shaw J, Ward RD. 1986. The ecology of Lutzomyia umbratilis Ward \& Fraiha (Diptera: Psychodidae), the major vector to man of Leishmania braziliensis guyanensis in north-eastern Amazonian Brazil. Bulletin of Entomological Research, 76, 21-40.

55. Rotureau B. 2006. Ecology of the Leishmania species in the Guianan Ecoregion Complex. American Journal of Tropical Medicine and Hygiene, 74, 81-96.

56. Ryan L, Lainson R, Shaw JJ. 1987. Leishmaniasis in Brazil. XXIV. Natural flagellate infections of sandflies (Diptera: Psycodidae) in Pará State, with particular reference to the role of Psychodopygus wellcomei as the vector of Leishmania braziliensis in the Serra dos Carajás. Transactions of the Royal Society of Tropical Medicine and Hygiene, 81, 353-359.

57. Sábio PB, Andrade AJ, Galati EAB. 2014. Assessment of the taxonomic status of some species included in the shannoni complex, with the description of a new species of Psathyromyia (Diptera: Psychodidae: Phlebotominae). Journal of Medical Entomology, 51, 331-341.

58. Saraiva JF, Souto RNP, Ferreira RMA. 2011. Flebotomíneos (Diptera: Psychodidae) coletados em um assentamento rural no Estado do Amapá, Brasil. Biota Amazônia, 1, 58-62.

59. Shaw JJ, Ishikawa EAY, Lainson R. 1989. A rapid and sensitive method for the identification of Leishmania with monoclonal antibodies using fluorescein-labelled avidin. Transactions of the Royal Society of Tropical Medicine and Hygiene, 83, 783-784.

60. Shaw JJ, Ishikawa EAY, Lainson R, Braga RR, Silveira FT. 1991. Cutaneous leishmaniasis of man due to Leishmania (Viannia) shawi Lainson, De Souza, Póvoa, Ishikawa \& Silveira in Pará state, Brazil. Annales de Parasitologie Humaine et Comparée, 66, 243-246.

61. Silva ACT, Cupolillo E, Volpini AC, Almeida R, Romero GAS. 2006. Species diversity causing human cutaneous leishmaniasis in Rio Branco, state of Acre, Brazil. Tropical Medicine \& International Health, 2, 1388-1398.

62. Silveira FT, Souza AA, Lainson R, Shaw JJ, Braga RR, Ishikawa EE. 1991. Cutaneous leishmaniasis in the Amazon Region: natural infection of the sand fly Lutzomyia ubiquitalis (Psychodidae: Phlebotominae) by Leishmania (Viannia) lainsoni in Pará state, Brazil. Memórias do Instituto Oswaldo Cruz, 86, 127-130.

63. Simon S, Veron V, Carme B. 2010. Leishmania spp. identification by polymerase chain reaction-restriction fragment length polymorphism analysis and its applications in French Guiana. Diagnostic Microbiology and Infectious Disease, 66, $175-180$

64. SINAN- Sistema de informação de agravos de notificação/ Secretaria de Vigilância e Saúde/ Ministério da Saúde:
Tabulação de Dados - Accessed on 04.03.2016. Available from http://dtr2004.saude.gov.br/sinanweb/index.php

65. Souza AAA, Santos TV, Jennings YLL, Ishikawa EAY, Barata IR, Silva MGS, Lima JAN, Shaw J, Lainson R, Silveira FT. 2016. Natural Leishmania (Viannia) spp. infections in phlebotomine sand flies (Diptera: Psychodidae) from the Brazilian Amazon region reveal new putative transmission cycles of American cutaneous leishmaniasis. Parasite, 32, 22.

66. Valderrama A, Tavares MG, Andrade Filho JD. 2011. Anthropogenic influence on the distribution, abundance and diversity of sandfly species (Diptera: Phlebotominae: Psychodidae), vectors of cutaneous leishmaniasis in Panama. Memórias do Instituto Oswaldo Cruz, 106, 1024-1031.

67. Valdivia HO, Santos MB, Fernandez R, Baldeviano GC, Zorrilla VO, Vera H, Lucas CM, Edgel KA, Lescano AG, Mundal KD, Graf PC. 2012. Natural Leishmania infection of Lutzomyia (Trichophoromyia) auraensis in Madre de Dios, Peru, detected by a fluorescence resonance energy transferbased real-time polymerase chain reaction. American Journal of Tropical Medicine and Hygiene, 87, 511-517.

68. van der Meide W, de Vries H, Pratlong F, van der Wal A, Sabajo L. 2008. Leishmania (Leishmania) amazonenis infection, Suriname. Emerging Infectious Diseases, 14, 858-859.

69. van Thiel P-PAM, van Gool T, Bart PA, Kager A. 2010. Case report: first cases of cutaneous leishmaniasis caused by Leishmania (Viannia) naiffi infection in Surinam. American Journal of Tropical Medicine and Hygiene, 82, 588-590.

70. Vexenat JA, Barretto AC, Cuba CC, Marsden PD. 1986. Características epidemiológicas da leishmaniose tegumentar americana em uma região endêmica do Estado da Bahia. III Fauna flebotomínica. Memórias do Instituto Oswaldo Cruz, 81, 293-301.

71. Walters LL, Chaplin GL, Modi GB, Tesh RB. 1989. Ultrastructural biology of Leishmania (Viannia) panamensis (=Leishmania braziliensis panamensis) in Lutzomyia gomezi (Diptera: Psychodidae): natural host-parasite association. American Journal of Tropical Medicine and Hygiene, 40, 19-39.

72. Walton BC, Shaw JJ, Lainson R. 1977. Observations on the in vitro cultivation of Leishmania braziliensis. Journal of Parasitology, 63, 1118-1119.

73. Ward RD, Fraiha H. 1977. Lutzomyia umbratilis, a new species of sand fly from Brazil (Diptera: Psychodidae). Journal of Medical Entomology, 14, 313-317.

74. Young DG, Duncan MA. 1994. Guide to the identification and geographic distribution of Lutzomyia sand flies in Mexico, the West Indies, Central and South America (Diptera: Psychodidae). Gainesville. Memoirs of the American Entomological Institute, 54, 1-881. 
Cite this article as: de Souza AAA, Barata IR, Silva MGS, Lima JAN, Jennings YLL, Ishikawa EAY, Prévot G, Ginouves M, Silveira FT, Shaw J \& Vasconcelos dos Santos T: Natural Leishmania (Viannia) infections of phlebotomines (Diptera: Psychodidae) indicate classical and alternative transmission cycles of American cutaneous leishmaniasis in the Guiana Shield, Brazil. Parasite, 2017, 24, 13.

\section{(0) PARASTE}

An international open-access, peer-reviewed, online journal publishing high quality papers on all aspects of human and animal parasitology

Reviews, articles and short notes may be submitted. Fields include, but are not limited to: general, medical and veterinary parasitology; morphology, including ultrastructure; parasite systematics, including entomology, acarology, helminthology and protistology, and molecular analyses; molecular biology and biochemistry; immunology of parasitic diseases; host-parasite relationships; ecology and life history of parasites; epidemiology; therapeutics; new diagnostic tools.

All papers in Parasite are published in English. Manuscripts should have a broad interest and must not have been published or submitted elsewhere. No limit is imposed on the length of manuscripts.

Parasite (open-access) continues Parasite (print and online editions, 1994-2012) and Annales de Parasitologie Humaine et Comparée (1923-1993) and is the official journal of the Société Française de Parasitologie. 